\title{
Protective effect of medicinal plants used in cancer prevention by traditional healers in Thailand
}

Natchagorn Lumlerdkij ${ }^{1,2}$, Ranida Boonrak ${ }^{2}$, Sukritta Pongsitthichok ${ }^{2}$, Hatthapan Wipanso ${ }^{2}$, Pravit Akarasereenont ${ }^{2}$, Michael Heinrich ${ }^{1}$

${ }^{1}$ Research Cluster Biodiversity and Medicines, UCL School of Pharmacy, 29-39 Brunswick sq., WC1N 1AX, London, UK, ${ }^{2}$ Center of Applied Thai Traditional Medicine, Faculty of Medicine Siriraj Hospital, Mahidol University, 2 Wanglang Road, 10700, Bangkok, Thailand

Based on a field work focusing on cancer prevention by traditional healers in Thailand suggested that prevention of oxidative stress is one of the key aims. Oxidative stress is involved with degenerative diseases, as well as cancer initiation and progression [1]. Therefore, protective effect against oxidative stress-induced cell death was used to investigate cancer chemopreventive properties of plant extracts.

HepG2 cells were incubated with plant extracts or (-)-Epigallocatechin gallate (EGCG) (positive control) at their non-toxic concentrations for 24 hours before an induction of the cell deaths using tert-butyl hydroperoxide ( $\mathrm{t}$-BHP). The Alamar Blue assay was used to determine the cell viability. After $0.5 \mathrm{mM}$ t-BHP treatment for 3 hours, the viability of non-pre-treated cells was around 30\%. EGCG at $50 \mu \mathrm{M}$ increased the viability to $48 \%$. Nineteen extracts increased the viability while twelve extracts decreased the viability and six of them had no effect. Water extracts from Terminalia bellirica (Gaertn.) Roxb. and Aucklandia lappa DC. gave the highest protection by increasing the viability to $59 \%$ and $54 \%$, respectively.

In conclusion, half of the extracts from plants used traditionally in cancer prevention possess protective effect against oxidative stress-induced cell death. Further pharmacological investigation based on the key strategy will provide more detailed scientific evidence for assessing these traditional medical methods in cancer prevention.

Acknowledgements: This project is supported by Faculty of Medicine Siriraj Hospital, Mahidol University, Bangkok, Thailand.

Keywords: cancer prevention, chemoprevention, traditional medicine, oxidative stress

\section{References:}

[1] Fiaschi T, Chiarugi P. Oxidative stress, tumor microenvironment, and metabolic reprogramming: a diabolic liaison. Int J Cell Biol 2012: 762825

Preferred presentation: $\square$ Oral $\quad \square$ Poster $\quad \square$ Young Researchers Workshop Presenter: Miss Natchagorn Lumlerdkij

\section{- Acceptable as poster}

